\title{
Emotional Instruments on Reading Novel using Social Media Among Indonesian Students
}

\author{
Nurhadi, Burhanuddin Tola, Riyadi
}

\begin{abstract}
Emotional reading instruments are tools to uncover variables or objects to obtain information about a person's feelings or thoughts while reading. The aim of the study was to develop a set of emotional instruments for novel readers. The research method uses product development research begun by instrument testing process to some respondents using social media in order to get the appropriate instruments in terms of the validity and reliability. The results obtained were emotional instruments reading literary works, in this case, novels, which are tested for validity and reliability, can be used to measure novel works. So, a novel reader can know his or her emotions toward the plot, characterization, point of view, background, message, and theme. Key Words: emotion, product development research, social media.
\end{abstract}

\section{INTRODUCTION}

It is widely known that emotional effects in reading both words and sentences can affect a person and the nature of the effects of emotions which depends on individual experience rather than the general affective nature of a word or sentence (Silva, Montant, Ponz, \& Ziegler, 2012). What makes reading novel complex is that as literary works, novel contains full of various lives experience and situation and certainly it will give an impact on the reader. Similarly, reading in social media can describe someone in real conditions, not infrequently. Reading through social media users devote their feelings or moods to a social media that can be measured one of which is the introduction of emotions on social media texts.(Aldy Rialdy Atmadja, 2019) In addition, other things related to literature, in this case the novel, namely psychology or better known as literary psychology. René and Austin explained that literary psychology has four possible studies, namely the psychology of the author as a person, the creative process, the types and laws of psychology applied to literary works, and the latter to study the impact of literature on the reader (reader psychology).(Taum Yoseph Yapi, 1997)

Furthermore, René and Austin stated that psychology can classify authors based on the type of psychology and Published By:

Blue Eyes Intelligence Engineering \& Sciences Publication

Revised Manuscript Received on November 15, 2019.

Nurhadi from Educational Research and Evaluation, Universitas Negeri Jakarta, Indonesia. My area of interest is social science, research and development.

Burhanuddin Tola from Educational Research and Evaluation, Universitas Negeri Jakarta, Indonesia. My area of interest is research and development.

Riyadi from Educational Research and Evaluation, Universitas Negeri Jakarta, Indonesia. My area of interest is research and development. physiology, they can describe their mental disorders, even their subconscious. This can be proven through documents outside of literature and from the literature itself. In literature, the psychological truth of a new literary work has artistic value if the work adds coherence and complexity to literary work, and psychological truth itself is a work of art. (Taum Yoseph Yapi, 1997)

The relation between psychology and literature, there are several things that need to be considered; the first literary work reflects strength, workmanship and expertise. Both literary works have special features in terms of language style and problem as a tool to express the thoughts and feelings of the author.(Keane, Graham, \& Burnes, 2014) The three problems of style, structure, and theme of literary works are interrelated with elements that reflect the thoughts and feelings of individuals, which include the main feelings, specialization, passion, enthusiasm and displeasure, which are continuous and cohesion to personality. argues that the expression in a novel is the personification of various impulses (stimuli or movements of the heart) and the emotions of the author as the relation between these elements in the narrative related to what is experienced by the author.(Eslinger, Moll, \& de Oliveira-Souza, 2003)

\section{Literature REVIEW}

Emotions refer to a feeling and thoughts typical of biological and psychological states and a series of tendencies to act. Emotions consist of cognitive processes that produce memories of an event and are strengthened by a state of mood.(Bookbinder \& Brainerd, 2016) Emotions usually occur when we feel a significant positive or negative change in our personal situation or in a situation related to us and also occurs when a change is considered relevant to our personal problems. Argues, someone who understands emotions equipped with emotional vocabulary can increase complex understanding of emotions that can accurately describe various feelings.(Eslinger et al., 2003)

There are several things related to the emergence of emotions in someone who just happens to happen, namely:(Simpson \& Marshall, 2010) (1) getting up in the morning and feeling depressed, but not knowing why, (2) being criticized by others then angry, (3) nervous when opening results health damage, heartbeat, and feeling sick, (4) hugging a pet and then feeling warm and comfortable, (5) walking midnight feeling tense when there is another voice behind, even running as fast as possible, (6) sometimes taking lessons and is interested but suddenly get bored due to the long duration (7) meet cheerful friends and invite

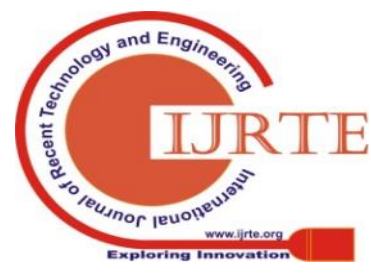




\section{Emotional Instruments on Reading Novel using Social Media Among Indonesian Students}

to drink and immediately feel more cheerful. Emotions into two types, first primary emotions, namely the extent to which emotional reactions connected from birth are afraid of large and wild animals (such as bears, snakes, spiders, etc.), as well as motion (in reptiles), sound (growl). Second, secondary emotions, namely emotions experienced by adults, such as imagining meeting a friend who has not met for a long time, will certainly feel an incomparable pain or be told about an unexpected death of a friend, maybe the heart is beating fast, mouth is dry, the skin pales, the part of the intestine contracts, the muscles in the neck and back tighten as a result of sadness.(Con Stough, 2000) There are three concepts of emotions including: "(1) Emotions are body reactions toward a specific situation. For example, when we feel something funny, then we laugh. But the physical reaction is the main clue. (2) Emotions are the result of a process of perception of the situation, if we perceive the condition of a traffic jam as a result of a reckless city bus driver then we will be angry. But if we accept it as something normal, we will be more calm. Thus, our emotions arise from the way we see or perceive things. (3) Emotions are the result of cognitive reactions (thinking). If the test gets closer, we might be afraid of failure. Then we begin to worry and study diligently (Fineman, 2003).

And there are eight different types of emotions, namely:

- Anger: violent, angry, hateful, irritated, disturbed, bitter, angry, offended, hostile, and perhaps the most intense, violent acts and pathological hatred

- Sadness: pain, sadness, gloomy, melancholic, self-loving, hopeless, lonely, rejected, if it is pathologically severe depression.

- Fear: anxiety, nervousness, worry, anxiety, feeling scared, alert, not calm, horrified

- Enjoyment: happy, joyful, carefree, satisfied, happy, entertained, proud, sensory pleasure, amazement, charm, satisfaction, feeling fulfilled, extraordinary joy, pleasure, great pleasure, great pleasure,

- Love: acceptance, friendship, trust, kindness, feeling close, devotion, respect, and love

- Shocked: gasped, surprised, amazed, stunned

- Irritated: insulted, disgusted, disgusted, nauseous, dislike, want to vomit

- Shame: shame, embarrassment, irritation, regret, contempt, disgrace, and broken heart.

Emotional benefits include; (1) functions as an energizer or energy generator so as to provide a passion in human life, after hearing a song or performance it will result in a loss of work; (2) as a messenger, for example seeing a child who smiles after school which contains a message that he or she is successful; (3) as a reinforce that is strengthening the message or strengthening the information conveyed, or reinforcing the information conveyed; (4) to balance the life balance so that it can maintain the homeostatic process (maintaining concentration) in a person (Rolls, 1999).

Reading is one of the language skills (listening, speaking, reading, and writing), both in the form of scientific essays and works of fiction. Reading is a process to obtain a message made by the reader. The main purpose in reading is to find and obtain information including the content and understanding the meaning of reading. Duke, N. K., \& Pearson, P. D suggested that reading with good understanding; the first reader is active, from the beginning he or she has a clear goal and constantly evaluates whether the text, and their reading, meets their goals.(Nell k. duke, 2009) Second, the reader examines the text before they read, taking notes such as the structure of the text and parts of the text that might be most relevant. Third, often make predictions about what will happen, Fourth, read selectively, what must be read carefully, what must be read quickly, what is ignored, what must be read again, and so on. Fifth, compile, revise, and question the meaning contained. Sixth, try to determine the meaning of words and unknown concepts in the text, compare and integrate their previous knowledge with the material in the text and evaluate the quality and value of the text, and react to the text in various ways, both intellectually and emotionally. Seventh, reading different types of texts differently. Eighth, text processing occurs not only during "reading", but also during short breaks on reading, even after "reading" activity has been stopped. So understanding reading is a time-consuming, continuous and complex activity, but the results are good, satisfying and productive for the readers themselves. Reading into two groups, first reading aloud and second reading in days. Reading in the heart is divided into two, first reading extensively (reading surveys, reading at a glance, and reading superficially)(Annisa, 2010), both intensive reading (reading the study of the contents and analysis of the language). Reading the contents, among others, reading carefully, reading comprehension, reading critically, and reading ideas, while reading the study of language, namely reading languages and reading literature.

Moreover, A.T. Recognizes three main things to read, first there are substantial variations in reports about reading experiences. Second, the reading experience reported varies with the type of reading: reading with dialogue encourages an increase in the inner conversation report, while reading with clear visual details encourages an increase in reports of visual imaging. (Pamela Sammons, 2006) Third, reports on the experience of visual imagery, inner experience, and experience of visual perception, the reader is aware of the weaknesses in understanding the pages of reading material that is not understood A novel is a story that tells an important part of human life followed by a change in fate. Abadul Rozak et al. explained, the type of pora novel that contains elements of characters, grooves, fictional backgrounds that spur human life based on the point of view and contain the value of life that is processed with narrative and demonstration techniques that become the writing convention. The novel, as one of the literary works of fiction as well as literary works, is a copyrighted work that provides the world in the form of autonomous words (subject to literary work itself not outside literary works), which have elements of events, plots, themes, characters, backgrounds, point of view, etc. While literature, according to Rene Wellek and Austin Warren, is a result of the creativity of a work of art.

(Lee Kuan Yew, 2003)

The following is an explanation of the intrinsic elements of the novel, including: First, the theme, as the basis of the story, is a general idea. (Nur, 2006)The theme of ideas, main thoughts, or points of discussion in literary works can be formulated in written statement 
(sentences). The level of theme according to Shpley, in Burhan, namely, (a) physical theme, (b) organic level, (c) social level, (d) egoic level, (e) divine level. Second, plot is the structure of a series of events in a story that are arranged as functional interrelations that mark the sequence of parts in overall fiction. Some expert opinions cited by Burhan, first, Stanton said that the plot is a story that contains the sequence of events, and each event is related to causation, one event caused by another event; second, Kenny explained that plots as events are displayed in the form of stories that are not simple, because the authors compile ceirta based on cause; third, Foster argues, that a plot is a story event that has an emphasis on a causality relationship. Third, characterizations or figures are people who play a role in literary works, while characterizations are the process of the character's appearance by giving the character, or habit of storytellers. The character of the story carries a certain character which is given the form and content of the author, and the expression can be seen through acts of horn and speech. Characterization of the technique of embodiment and the development of characters in a story. Fourth, background: the environment of the place, room, time, period, season and the like in that story the event occurred. Abrams, in Burhan, explains that the background is the place, time relationship, and social environment where events are told. Sometimes it is interrelated or not between one background and another (place, time, and social environment that becomes a story), but it is still in the realm that supports the plot (storyline). Fifth, the point of view in a literary work is the way the author places his or her position in the story being wrote (generally in the novel it is divided into the point of view of the first person and the third person's point of view). Viewpoint is a strategy, technique, tactics that the author chooses to tell stories.

Sixth, style is a disclosure method in prose or poetry which includes diction, majas, rhetorical means, sentence forms and paragraphs. Style is the method, technique, or form of the author to convey the idea. The division of novels according to Burhan are two, namely serious novels and popular novels. Generally, serious novels are published by publishers who are known as publishers of literary books and have high literary quality and are able to provide all possibilities. In addition, the experiences and problems of life are displayed to the core of the universal essence of life. Meanwhile, popular novels or also called pop novels, usually as mere entertainment literature, which is only popular in its time, did not record lives. This type of novel is popular with teenagers because it is easy to read. According to Liberatus Tengsoe Tjahjono, the romance (this term is only in Indonesia, generally referred to as novels) includes: (1) historical romance, which is written based on historical facts and combined with the imagination of Abdul Muis's Suropati author, (2) tendency to romance story namely romance which aims to improve the inequality that occurs in the community, for example Siti Nurbaya Karya Marah Rusli, (3) psychological romance which is a novel that presents the struggle of the soul of an example of Atheist by Achdiat Kartamiharja, (4) deductive romance which is an attempt by law enforcers to eradicate crime Virgin Child Thief by Suman Hasibuhan, (5) traditional romance or regional romance, namely a story that raises the customs or traditions of a community in the area of the example of Sukreni Bali Girl by I Gusti Nyoman Panji Tisna, (6) social romance which is a romance that presents stories that depart from relations humans with a social environment, examples of the Drought by AA Navis, (7) a struggle story that is giving the Indonesian nation's struggle both physically and mentally to gain independence, for example, Man and Gunpowder by Trisnojuwono, (8) female romance, a romance that tells the life journey of both born and inner women, example Dwisari Teacher by Umar Nur Zain, (9) children's romance children are romances that tell the lives of children with their funny, joyful behavior, until the adventures of the example of Kiki and his Komplotan by Arswendo, and (10) symbolic romance which is a type of story which describes inner or metaphysical experiences, not experiences of world facts such as Red, The Pilgrimage and Dryness are all the work of Iwan Simatupang.

\section{Methodology/Materials}

The procedure for developing emotional instruments to read novels is described as follows:

- Development of constructs based on theories or concepts about emotional characteristics

- Development of conceptual and operational definitions of the emotional variables of reading novels, as psychological responses based on constructs constructed by researchers.

- Choose a scale that is relevant to the emotions of reading a novel that will be measured in each dimension of emotion reading a novel; anger, sadness, fear, pleasure, love, surprise, annoyance, and shame at the intrinsic elements of a novel's work.

- Compile instrument specification tables or instrument grids containing dimensions, indicators, positive and negative item numbers, and number of items.

Arranging the points of emotional instruments to read novels based on the chosen scale, then confirm the readability of the instrument items to the promoter.

- Trials to panelists by asking for expert and professional considerations to see the accuracy and inaccuracies between indicators with dimensions and between indicators and items, after which item analysis and item revision.

- Empirical trials for Indonesian Language and Literature study program students were carried out in two stages, then determining construct validity with structural equation modeling and determining reliability with construct reliability (CR) and multidimensional reliability with McDonald's composite score reliability.

- Establish guidelines and scoring techniques on emotions reading novels according to scoring standards.

- Produce emotional instruments to read novels that are valid and reliable.

Furthermore, in scoring of psychological scale construction, it is determined by the scale used. Selection of scale is the process of determining the location of stimulation and response on a psychological continuum. This research uses attitude scale and rating scale.

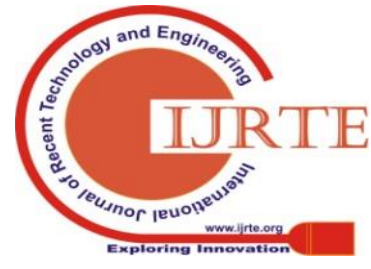




\section{Emotional Instruments on Reading Novel using Social Media Among Indonesian Students}

The attitude scale can be used to measure attitudes, opinions and one's perceptions of an object. This is done because the researcher chooses the attitude scale for the theoretical trial instrument or expert validation, it can be used to find out the expert opinion on the suitability of dimensions, indicators and items that have been set in the emotional instruments of reading novels. The asses sment is carried out by expert judgment or experts including practitioners or experts in the field of psychology, education measurement experts, lecturers in Indonesian Language and Literature courses, and Indonesian linguists. These experts are required to provide estimates of the positive degrees of each statement according to a psychological continuum rather than giving consent or not agreeing individually. Scores range from 1 to 5, namely if the positive degree of statement is very high or very suitable between dimensions and indicators given a score of 5. On the contrary, if the positive degree of statement is very low or very inappropriate between dimensions and indicators then it is given a score of 1 . The response approach is used to see students against the object they are facing, namely the literary work they read. Measurement of student responses to certain objects can be done using a questionnaire with a differential semantic scale. Soňa Divilová explained that differential semantics is a research equipment that can measure definite psychological meaning in objects (most concepts) possessed by individuals.

The development of emotional instruments for reading novels requires research instruments. The measurement of emotions in reading a novel cannot be directly measured because it is intangible or hidden, therefore it requires an instrument or a data collection tool. The instruments are aids in measuring, so data or objects to be measured can be collected. Furthermore, according to Widiyoko, the instrument is a tool used by researchers to collect data. This is in line with Purwanto, the research instrument is a measuring instrument used to collect data. According to Nitko, measurements are defined as a procedure of assigning numbers to a specific attribute or characteristic of the possessing the attribute. Measurements, explained by Miller, Linn and Gronlund, are assigning numbers to the results of a test of type of assessment according to a specific rule. Meanwhile, Reynold devines measurement as Living stone. Willson contends that measurements are a set of rules for assigning numbers to represent objects, traits, attributes, or behavior. Furthermore, validity test of measuring instrument is done in two ways; To test the validity of the theory and test the validity empirically. Validity testing theoretically involves experts, while empirical trials involve respondents, they are students of Indonesian Language and Literature Study Program in DKI Jakarta. Theoretical validity testing requires an instrument trial to the expert. The task of the expert is to assess the suitability between the dimensions and indicators between the indicators and items of the instrument. Expert assessment is given qualitatively, while panel assessment is given quantitatively. The validity of experts in this study involved literary experts, namely practitioners and medical experts and linguists and doctors from the Universitas Negeri Jakarta Education Research and Evaluation program and doctoral candidates from Universitas Negeri Jakarta.

\section{RESULTS AND FINDINGS}

The results obtained in this study are the emotional instruments of reading novels in the form of a questionnaire that refers to various theories about emotions from conceptual theory. Based on the concept or theory of emotion and regulated by literature, it is determined 8 (eight) dimensions, namely (1) anger, (2) willingness, (3) fear, (4) pleasure, (5) love or affection, (6) surprised , (7) annoyed, and (8) embarrassed. Each dimension has indicators, namely:

- $\quad$ anger, consisting of 48 item indicators

- availability, consisting of 48 item indicators

- fear, consisting of 3 indicators 6 items

- $\quad$ enjoyment, consisting of 3 indicators 6 items

- $\quad$ love, consisting of 48 item indicators

- $\quad$ surprised, consisting of 2 indicators 4 points

- $\quad$ annoyed, consisting of 4 indicators and 8 items

- embarrassment, consisting of 2 indicators 4 points

Thus, the total item of all emotional dimensions of reading a novel is $\mathbf{5 2}$ (fifty two) items.

Emotional measurement of reading novel is an activity of giving numbers to the emotions of reading, to obtain numbers in literary works, in this case a novel is needed as an instrument in which there are theoretical constructs, consisting of conceptual definitions, operational definitions, instrument, emotional dimensions of reading novels, emotional indicators of reading novels, as well as items of emotional instruments to read novels. Based on a number of theories about the emotions of reading novels, which includes about the characteristics of emotions, the emotional construct is determined to read novels

Table. Conceptual Definition of Reading Emotion Novels

\begin{tabular}{|c|c|c|c|c|}
\hline No. & Dimension & Indicator & No of item & Total \\
\hline 1 & Anger & $\begin{array}{c}\text { Hate the character, plot, } \\
\text { settings, and use of language } \\
\text { styles }\end{array}$ & $\begin{array}{l}1,2.3,4,5,6 \\
\quad 7,8\end{array}$ & 8 \\
\hline 2 & Misery & $\begin{array}{l}\text { Sad on the theme, on characters, } \\
\text { grooves, story settings }\end{array}$ & $\begin{array}{r}9,10,11,12 \\
13,14,15,16\end{array}$ & 8 \\
\hline 3 & Fear & $\begin{array}{l}\text { Anxious about characters, } \\
\text { grooves, story settings }\end{array}$ & $\begin{array}{c}17,18,19,20 \\
21,22\end{array}$ & 6 \\
\hline 4 & Pleasure & $\begin{array}{l}\text { Happy about the plot, settings, } \\
\text { and style of language }\end{array}$ & $\begin{array}{l}23,24,25,26 \\
27,28\end{array}$ & 6 \\
\hline 5 & $\begin{array}{l}\text { Love or } \\
\text { Affection }\end{array}$ & $\begin{array}{l}\text { A sense of close to the theme, } \\
\text { character, plot, story setting }\end{array}$ & $\begin{array}{l}29,30,31,32 \\
33,34,35,36\end{array}$ & $\begin{array}{l}2 \\
6\end{array}$ \\
\hline 6 & $\begin{array}{l}\text { Amazed/ } \\
\text { surprised }\end{array}$ & $\begin{array}{l}\text { Be amazed at the plot and story } \\
\text { settings }\end{array}$ & $37,38,39,40$ & 4 \\
\hline 7 & Annoyed & $\begin{array}{l}\text { Fed up with character, plot, } \\
\text { setting, and language style }\end{array}$ & $\begin{array}{l}41,42,43,44 \\
45,46,47,48\end{array}$ & $\begin{array}{l}4 \\
8\end{array}$ \\
\hline \multirow[t]{2}{*}{8} & Shame & $\begin{array}{l}\text { Insulted by the storyline } \\
\text { character }\end{array}$ & $49,50,51,52$ & 4 \\
\hline & & & Total & 52 \\
\hline
\end{tabular}

The conceptual definition of emotional novel reading is a person's emotions after reading a work, which involves the structure of literary works, namely the theme, plot, characterization, setting, point of view, and author's style in creating literary works.

\section{A. Definition of conceptual Emotion of Reading Novels}

Defining the conceptual emotions of novel reading is a score obtained through a questionnaire on student students after reading literature based on the structure of the novel, anger, (character, plot, setting, 
language style), availability (theme, character, plot, setting), fear (figure, groove, setting), enjoyment (plot, setting, language style), love (theme, character, plot, setting), surprise (plot, setting), annoyance (character, plot, setting, style), and shame (figure, plot).

The design and the distribution of the item numbers of the emotion measuring instrument of reading novel is in the following table:

Table. Emotion Instrument of Reading Novels

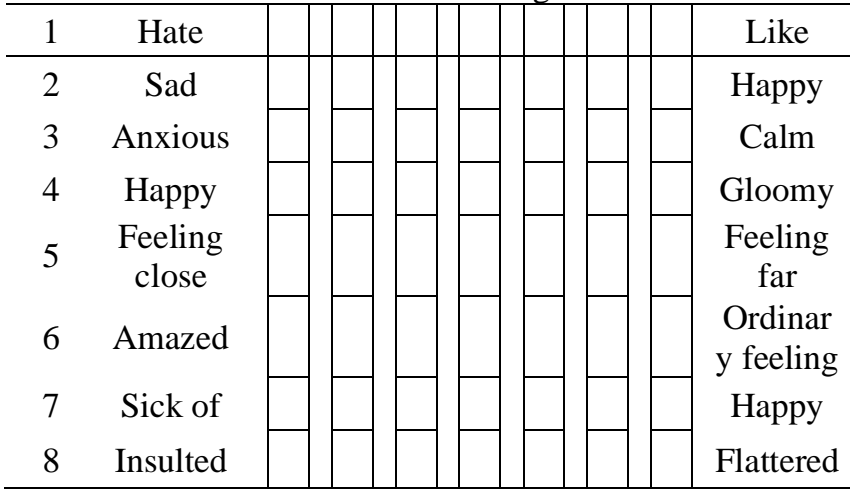

\section{Conclusion}

The development of emotional instruments of reading novels using social media will make it easier for researchers or for anyone who wants to develop an instrument. This emotional instrument is associated with reading literary works and non-literary works (scientific works). The use of a differential semantic scale is one of the scales that can express one's emotions or feelings through tendencies within the reader his or herself including emotional choices that not only reveal negative emotions or just positive. Then, even the positives of the instrument should be relatively balanced.

\section{ACKNOWLEDGements:}

The researchers would like to say thanks to Sulfikar Sallu ID Scopus 57200989289 doctoral students of Educational Technology, State University of Jakarta and Lecturer at the Faculty of Information Technology, University of Nineteen November, Kolaka, Southeast Sulawesi for his great contribution on the research completion.

\section{REFERENCES}

1. Aldy Rialdy Atmadja. (2019). Studi Pengembangan Model Pengenalan Emosi Pada Teks Media Sosial. Jurnal Algoritma, 4, 6.

2. Annisa, N. (2010). A Comparison Between Readng Aloud and Silent Reading in Undenstanding Recount text. 98.

3. Bookbinder, S. H., \& Brainerd, C. J. (2016). Emotion and false memory: The context-content paradox. Psychological Bulletin, 142(12), 1315-1351. doi:10.1037/bul0000077

4. Con Stough, D. H. S., James D.A Parker, . (2000). Assessing Emotional Intelligence. book, 376.

5. Eslinger, P. J., Moll, J., \& de Oliveira-Souza, R. (2003). Emotional and cognitive processing in empathy and moral behavior. Behavioral and Brain Sciences, 25(1), 34-35. doi:10.1017/s0140525x02360011

6. Fineman, S. (2003). Understanding Emotion at Work. book, Sage Publisher, 215

7. Keane, J. F., Graham, G., \& Burnes, B. (2014). Literary praxiphorical analysis: Using science fiction and fantasy to shape organizational futures. Technological Forecasting and Social Change, 84, 54-65. doi:10.1016/j.techfore.2013.10.025

8. Lee Kuan Yew, H. K. e. a. (2003). Crossing between Old and New Nations. Asia Europe Journal, 3, 56.
9. Nell k. duke, P. D. P. (2009). Effective Practices for Developing Reading Comprehension. J O U R N A L O F E D U C A T I O N, 189(1), 16.

10. Nur, D. R. (2006). AN ANALYSIS OF INTRINSIC ELEMENTS ON JAMES JOYCE SHORT STORY.

11. Pamela Sammons, L. B. (2006). Effective teaching. Education Development Trust.

12. Rolls, E. T. (1999). The Brain and Emotion. book, Oxford University, 379.

13. Silva, C., Montant, M., Ponz, A., \& Ziegler, J. C. (2012). Emotions in reading: disgust, empathy and the contextual learning hypothesis. Cognition, 125(2), 333-338. doi:10.1016/j.cognition.2012.07.013

14. Simpson, B., \& Marshall, N. (2010). The Mutuality of Emotions and Learning in Organizations. Journal of Management Inquiry, 19(4), 351-365. doi:10.1177/1056492610376531

15. Taum Yoseph Yapi. (1997). Pengantar Teori Sastra. Buku, 44.

\section{AUTHORS PROFILE}

Nurhadi from Educational Research and Evaluation, Universitas Negeri Jakarta, Indonesia. My area of interest is social science, research and development.

Burhanuddin Tola from Educational Research and Evaluation, Universitas Negeri Jakarta, Indonesia. My area of interest is research and development.

Riyadi from Educational Research and Evaluation, Universitas Negeri Jakarta, Indonesia. My area of interest is research and development. 